\title{
Diplomáticos, periodistas, espías y publicistas: la cruzada mexicana-bolchevique en América Latina
}

Pablo YANKELEVICH*

\begin{abstract}
Resumen: Hacia mediados de la década de 1920, sectores importantes de la administración del presidente John Calvin Coolidge y de la opinión pública norteamericana, estuvieron convencidos de que México estaba gobernado por una camarilla comunistas. Esta percepción tuvo su origen en un irresuelto conflicto que los revolucionarios mexicanos sostuvieron con gobernantes y empresarios norteamericanos desde la promulgación de la Constitución de 1917; a lo que se sumó una serie de actitudes del presidente Calles desafiando a sectores conservadores de la sociedad mexicana junto a poderosos intereses estadounidenses. En este texto se estudian las estrategias y los personajes que contribuyeron a gestar la idea de un Méxicosoviet, prestando una particular atención al trabajo desarrollado por espías al servicio del gobierno norteamericano, pero también a la labor de intelectuales que bajo protección callista llevaron cabo una muy difundida obra de carácter anticlerical y antiimperialista.
\end{abstract}

Palabras clave: México; Revolución; Comunismo; Anticomunismo; Propaganda; Espionaje.

Una mañana de enero de 1927, el embajador James Sheffield revisaba la correspondencia que horas antes el servicio postal había depositado en el buzón de su residencia en la capital mexicana. De entre todas las cartas se detuvo en un sobre amarillento que de inmediato abrió para extraer un panfleto.

- Instituto Nacional de Antropología e Historia, México - INAH - 06100

- Colonia Hipódromo - México. E-mail: pabloy@servidor.unam.mx

HISTÓRIA, São Paulo, 28 (2): 2009 
Escrito en tinta roja, un párrafo confirmó las razones de una preocupación que desde hacia más de un año se había instalado en las oficinas del Departamento de Estado: "El esfuerzo del pueblo mexicano ensayando escapar de las garras del imperialismo yankee enseña a los demás pueblos de Centro y Sudamérica la lucha contra la sujeción y explotación del imperialismo norteamericano." ${ }^{1} \mathrm{El}$ panfleto llevaba la firma de la Liga Antimperialista de las Américas.

La coyuntura mexicana de 1926-1927 sirvió de excusa al gobierno norteamericano para un montaje que con dos décadas de anticipación caracterizaría las paranoicas atmósferas de la Guerra Fría. En aquel entonces, el gobierno presidido por Plutarco Elías Calles fue valorado como una amenaza de dimensiones comparables a la alejada Rusia de los soviets. James Sheffield, en representación de la vertiente más dura de la diplomacia del dólar, fue uno de los responsables de proyectar aquella idea, de la que por cierto estuvo firmemente convencido. En agosto de 1926 escribió al Secretario de Estado Frank Kellog: "el gobierno de México es verdaderamente bolchevique y trata de expandir las doctrinas comunistas no solo a los países vecinos de Centroamérica, sino a Sudamérica y parte sur de los Estados Unidos". ${ }^{2}$

Hasta finales de los treinta, y a escala continental, México con su Revolución constituyó en el mayor desafío a la política estadounidense en América Latina. ${ }^{3}$ La Constitución de 1917 sentaba precedentes para amenazar jurídicamente a propiedades e inversiones norteamericanas, y durante más de tres años, el gobierno de Álvaro Obregón demostró al mundo que la negativa de Washington a otorgarle el reconocimiento diplomático estuvo lejos de constituir un obstáculo para la consolidación del régimen posrevolucionario. Pero además, a comienzos de los años veinte, se inauguró una reforma agraria que afectaron propiedades de ciudadanos norteamericanos y; al promediar aquella década se aprobó una legislación petrolera que lesionó seriamente los intereses estadounidenses. En los medios empresariales la inquietud por los desbordes sindicales crecía en la misma proporción con que el gobierno 
DIPLOMÁTICOS, PERIODISTAS, ESPÍAS Y PUBLICISTAS:...

callista auspició a la ya entonces poderosa Confederación Regional Obrera Mexicana. Y por si esto fuera poco, el anticlericalismo gubernamental condujo a un inaudito boicot decretado por los jerarcas de la iglesia que dejó sin servicios de culto al pueblo más católico de América.

Pero también, en aquellos veintes y antes que ninguna otra nación del continente, México estableció relaciones con la URSS $^{4}$. Además, en territorio mexicano encontraron refugio perseguidos políticos de dictaduras y dictadores latinoamericanos: el cubano Julio Antonio Mella, el peruano Víctor Raúl Haya de la Torre, el venezolano Salvador de la Plaza, el boliviano Tristán Marof, y toda una pléyade de perseguidos centroamericanos. En México se confabuló, y en el caso de la Nicaragua de Sandino esa práctica contó con la solidaridad y el apoyo militar del gobierno mexicano.

Hacia 1926, el gobierno de Calles había transgredido las fronteras de lo tolerable por la Casa Blanca, fue entonces que la administración del presidente Calvin Coolidge pasó a interpretar la apoteosis del radicalismo callista como la cristalización de un programa bolchevique. Si el nacionalismo agrícola y petrolero, el activismo sindical y el anticlericalismo servían de fundamento para tal calificativo, ¿cómo se construyó la idea de que un gobierno que a duras penas podía iniciar un proceso estabilización política y reordenamiento económico, sería además capaz de liderar una cruzada bolchevique a escala hemisférica?.

El temor norteamericano de que el comunismo se expandiría desde México al resto del continente, tenía su origen en una estrategia que los revolucionarios pusieron en marcha una década antes de que Calles llegase a la presidencia. Hacía 1924, ya era perceptible el impacto de la revolución mexicana en América Latina, y ese impacto fue consecuencia de una sistemática campaña propagandística diseñada originalmente por el constitucionalismo, y que más tarde encontró continuidad en los distintos gobiernos legitimados al amparo de la Constitución de 1917. El objetivo central de esta campaña fue dar respuesta a otra, de origen norteamericano, que desde mediados de la década de 1910 se empeñó en descalificar la lucha revoluciona- 
ria, buscando justificar ante la opinión pública internacional una tradicional política intervencionista.

Con este diseño propagandístico los revolucionarios mexicanos trataron de construir una retaguardia internacional de la Revolución, y para ello pusieron en práctica dispositivos tendientes a ganar aliados, adeptos y publicistas. Entre ellos, los verdaderamente convencidos en las virtudes de la Revolución fueron los responsables de insertar la cuestión mexicana en la agenda política y cultural del continente. Es decir, la revolución mexicana en América Latina fue tema de reflexión hasta convertirse en objeto de prácticas políticas, todo ello gracias a un esfuerzo mexicano tendiente a difundir los objetivos y características de la gesta armada rectificando noticias mañosamente trasmitidas desde Estados Unidos. Pero además, este esfuerzo propagandístico se desenvolvió en un contexto latinoamericano particularmente receloso a las políticas de Washington. En tal sentido, y con intensidad variable, el abierto desafío a la voluntad imperial de una política mexicana sustentada en criterios nacionalistas en materia económica, pero también altamente original en cuestiones de legislación social, propuestas educativas y proyectos culturales, comenzó a adquirir contornos ejemplificadores, que desde mediados de los años veinte decantaron en conductas y programas políticos de corte nacionalista, latinoamericanista y antimperialista.

Durante el cuatrienio callista, ánte el ascendente conflicto con los Estados Unidos, se incrementó el esfuerzo mexicano por fortalecer la presencia de México en América Latina. Para ello y particularmente en un intento por ganar espacios en la prensa latinoamericana, se acrecentó el envío de libros, boletines y folletos. Tal sólo en el primer año de gobierno de Calles fueron remitidos al exterior "230.000 paquetes de libros y publicaciones periódicas". Entre el conjunto de estos impresos, estuvieron los primeros ejemplares de la colección Monografías Bibliográficas Mexicanas, colección creada por la propia cancillería mexicana para divulgar las novedades editoriales. ${ }^{5}$ Es de observar que no pocas bibliotecas latinoamericanas y particularmente las de América Central, vieron engrosar sus acervos con estas 
DIPLOMÁTICOS, PERIODISTAS, ESPÍAS Y PUBLICISTAS:...

donaciones. ${ }^{6}$ A este aluvión de impresos, se sumaron los boletines de prensa que elaboró la Agencia Mexicana de Noticias, quizás el antecedente más remoto de la oficialista NOTIMEX. En 1927, de este Boletín se distribuyeron cerca de un millar y medio de ejemplares. ${ }^{7}$

Este esfuerzo incrementó el flujo de noticias y aportó nuevas fuentes informativas a periodistas, escritores e intelectuales de América Latina, labor que muchas veces estuvo acompañada de un generoso mecenazgo que garantizó la publicación no sólo de notas de prensa, sino de obras mayores de carácter apologético. Entre otros casos, destaca el apoyo que recibió el costarricense Amado Chaverri Matamoros director del Departamento de Prensa de la Secretaria de Gobernación entre 1925 y 1927. En esos años con financiamiento de esa Secretaría, este funcionario editó la revista México y Centroamérica dedicada a la condena de la política estadounidense en la región y a la promoción de la unión centroamericana. ${ }^{8}$ Chaverri Matamoros, recibió ayuda de Calles para este proyecto así como para la publicación de El verdadero Calles, (México, 1933) cuyo subtítulo en nada disimula la intención de la obra: Materiales para el futuro historiador sobre la personalidad y la actuación del Sr. Gral. Plutarco Elías Calles, Jefe de la Revolución Mexicana, y hoy por hoy el hombre fuerte del continente por antonomasia. Algo más de un centenar de respuestas, opiniones y comentarios dan cuerpo a un libro de casi medio millar de páginas. Sucede que Chavarri Matamoros, periodista al fin, distribuyó una encuesta dedicada a la vida y obra de Calles con la evidente intensión de construir un héroe a la medida de los dictados de Thomas Carlyle. Es por ello que en las páginas de aquel libro desfilan juicios emitidos por militares, embajadores, secretarios de Estados, jueces, escritores, líderes obreros, periodistas mexicanos y extranjeros, en un mosaico que a todos incluye desde el testimonio de su secretaria Soledad González de Ayala González (Cholita) hasta las opiniones del presidente alemán Friedrich Ebert. Todo ello junto una frondosa iconografía, discursos, entrevistas, notas y glosas diversas.

De alguna manera, el costarricense se inspiró en otro de los libros jugosamente patrocinados por Calles. Se trató de Mexico HISTÓRIA, São Paulo, 28 (2): 2009 
before the World, Public Documents and Addresses of Plutarco Elías Calles, (New York, Academy Press, 1927) a cargo del periodista estadounidense Robert Hammond Murray, quien compiló una serie de artículos y discursos de Calles precedidos de una nota muy elogiosa que llevó la firma del argentino José Ingenieros. ${ }^{9}$ Este libro, conoció también una edición en español a cargo de Esperanza Velásquez Bringas, que en el desempeño de la jefatura del departamento de bibliotecas de la Secretaría de Educación Pública, cuidó la edición de México ante el Mundo. Ideología del presidente Plutarco Elías Calles, publicado en Barcelona también en 1927.

Quizá la empresa más ambiciosa de estos mecenazgos editoriales fue La iglesia católica ante la crítica en el pensamiento y en el arte (México, 1929) del italiano Guillermo Dellhora. Este personaje vendió a Calles un ambicioso proyecto tendiente a la edición de cuatro libros dedicados a exhibir la inmoralidad, el oscurantismo, la venalidad y el fanatismo de la institución papal a lo largo de la historia. De los cuatro libros ${ }^{10}$ solo uno fue publicado: La iglesia católica ante la crítica en el pensamiento y en el arte, en una edición lujosísima, con un tiraje de casi 30 mil ejemplares que estuvo por completo orientada a recopilar escritos de figuras del liberalismo de Europa y América, a exhibir una notable colección de dibujos y caricaturas anticlericales, como a demostrar el contenido erótico en algunas esculturas en los altares de los principales templos de la cristiandad. El libro fue profusamente distribuido por América Latina y Europa, espacios donde cosechó elogios de personalidades como Manuel Ugarte, Máximo Gorki, Sergio Eisenstein, y Henri Barbuse. Este último, en una nota publicada en la revista Monde, apuntó:

En América española se asiste a hechos de fanatismo y de oscurantismo que recuerdan la edad media. México, en 1926, vio a hordas negras, instrumentos de los curas, ensangrentar el país al grito de viva Cristo Rey. No hay crímenes que no hayan cometido estos fanáticos, que en un momento dado alcanzaron el número de treinta mil y que durante tres años asolaron a México. ${ }^{11}$ 
DIPLOMÁTICOS, PERIODISTAS, ESPÍAS Y PUBLICISTAS:...

La difusión del libro resultó tan exitosa que no tardó en ser incluido en la lista de impresos prohibidos por el Vaticano. Al promediar enero de 1930, Dellhora escribió a Calles:

Estoy satisfecho de que mi libro patrocinado por Ud. con tanto entusiasmo y fe completa, no haya defraudado los esfuerzos ni los sacrificios. La edición está prácticamente agotada por el público de México, Centro y Sudamérica. Creo que pronto circulará en Estados Unidos, pues Upton Sinclair, el popular socialista escritor, tan pronto recibió el ejemplar que le envié, se interesó en traducirla, y estamos tratando de hacer allá un amplio tiraje. ${ }^{12}$

Meses más tarde, se dirigía a Carlos Riva Palacio, entonces Secretario de Gobernación, para solicitar trabajo, un sueldo fijo y una secretaria, a los fines de" difundir las doctrinas de la revolución, [por ...] las naciones hermanas de esta América latina." ${ }^{13}$ Dellhora propuso desempeñar a cambio de una remuneración, "actividades disimuladas en la tarea desfanatizadota". ${ }^{4}$ Y finalmente, inspirado en la figura del socialista italiano Guido Prodecca, y su bien conocido diario $L^{\prime}$ Asino, consiguió apoyo para la publicación de un periódico anticlerical, El Asno, que editó en Jalapa, con un tiraje de 6 mil ejemplares y una distribución que alcanzó a Centroamérica. ${ }^{15}$

Durante el cuatrienio callista, la propaganda de la CROM en el extranjero fue la responsable de dotar de un áurea obrerista a la gestión gubernamental. Líderes sindicales de Europa, Estados Unidos y América Latina fueron invitados a conocer el país y en calidad de observadores participaron en reuniones, congresos y asambleas de aquella central obrera. Como parte de esta política y en la búsqueda de espacios donde difundir realizaciones gubernamentales, en 1925 fueron creadas las agregadurías obreras adjuntas a las representaciones diplomáticas. Calles explicó el sentido de estos nombramientos: "el objeto de estos funcionarios será el de estudiar cuidadosamente el desarrollo social de los países donde estén comisionados, para rendir informes oportunos al Gobierno, especialmente sobre legislación del trabajo, previsión social, y 
en general sobre el movimiento obrero, y al mismo tiempo establecer relaciones entre esos elementos y los similares de México. ${ }^{16}$ Carlos Gracidas, linotipista y diputado al Congreso Constituyente de 1917 fue enviado al sur del continente, y durante casi tres años de residencia en Argentina y de periódicos viajes a Chile y Uruguay cumplió a cabalidad con los objetivos apuntados por el presidente mexicano. El agregado obrero, participó activamente en los medios sindicales de matriz socialdemócrata, y por la naturaleza de sus actividades, estas se significaron como una auténtica trasgresión al formalismo de los ambientes diplomáticos. El activismo de Gracidas en medios obreros del continente, no pudo más que ensanchar las "evidencias" de que estaba en marcha una auténtica una cruzada bolchevique de origen mexicana. ${ }^{17}$

Estas costosas campañas de propaganda fueron motivo de vigilancia y preocupación por parte del gobierno estadounidense. Una enmarañada red de espionaje atravesaba a México. La embajada norteamericana en esta capital generaba información, pero también recibía información referente a México que era enviada por el servicio exterior estadounidense en Europa y América Latina. A su vez, el propio gobierno mexicano tenía una nada despreciable red de espías que daban cuenta de la información que remitía o recibía el embajador Sheffield. 10B el "gran espía de México" como lo llamó Friedrich Katz ${ }^{18}$, no fue el único aunque sin duda fue el espía que con mayor osadía penetró las líneas enemigas. Las pistas que dejaron estos informantes son útiles para entender el significado que el gobierno estadounidense otorgó a la propaganda mexicana

En enero de 1926, John S. Martin, encargado de negocios norteamericano en Madrid, informaba que Luis Araquistain, "un escritor profesional, que supongo está pagado por la legación mexicana, escribe en El Sol y aboga por la extensión del principio de nacionalización del subsuelo en todos los países hispanoamericanos. Sostiene que las republicas hispanoamericanas pueden poner un dique capaz de detener la ola de imperialismo de ciertos extranjeros." ${ }^{19}$ Meses más tarde, la embajada norteamericana en San Salvador, remitió al Departamento de 
Estado copia de un articulo titulado "Odio a los Estados Unidos" publicado por un "periódico que recibe dinero del gobierno mexicano [...] para hablar de la necesidad de boicotear comercialmente a los Estados Unidos y estrechar relaciones con Europa. ${ }^{20}$ No muy distintos fueron los informes norteamericanos sobre editoriales aparecidos en La Nación de Santiago de Chile, como aquel publicado en febrero de 1926 bajo el título de "La legislación nacionalista de México y su repercusión en EEUU", que no podía disimular en su factura la presencia de fuentes de información proporcionadas por el gobierno mexicano. ${ }^{21}$

En el terreno de la diplomacia formal, la cancillería mexicana durante el gobierno de Calles consiguió el viejo anhelo de elevar a rango de embajadas las representaciones en Argentina, Chile, Cuba y Guatemala, además de establecer relaciones diplomáticas con Ecuador. Estos logros no pasaron desapercibidos para el Departamento de Estado, quien desde inicios de los años veinte había valorado negativamente el intento mexicano de estrechar relaciones con las naciones más fuertes de Sudamérica. En un boletín confidencial del Departamento de Estado, interceptado por un espía al servicio del gobierno mexicano en Estados Unidos, se apuntaba que con el exitoso empeño por elevar a rango de embajada las representaciones en Buenos Aires y en Santiago de Chile "México se asegura una firme base para su política internacional en aquel continente."122

Sin lugar a dudas, el apoyo de México a la lucha que libraron los liberales nicaragüenses fue la mayor perturbación que realizó Calles a la política norteamericana en la región. Las operaciones de embarque de armas y municiones, como los contactos entre la dirigencia sandinista y el gobierno mexicano fueron convertidos en pruebas fehacientes de la ingerencia "bolchevique" mexicana en América Latina. Estos hechos desataron un auténtico escándalo que llenó páginas de la prensa, motivó audiencias en el Congreso estadounidense y estuvo a punto de activar una intervención armada de Estados Unidos contra un gobierno mexicano. Estos asuntos han sido objeto de variadas reconstrucciones históricas, ${ }^{23}$ sin embargo junto al caso nicaragüense se desplegó una intricada red de informaciones, quizá menos conocidas, que aportaron ideas 
e imágenes de un México que supuestamente osaba poner en duda la hegemonía norteamericana en la región.

En enero de 1926, el embajador Sheffield escribió un largo informe confidencial dirigido a su jefe, Frank Kellog. En este documento indicaba que en respuesta a la designación en el verano pasado del propio Kellog como Secretario de Estado, Calles había puesto en marcha un plan cuidadosamente seguido por la Secretaria de Relaciones Exteriores. "Fuentes fidedignas" nunca reveladas por el embajador, alertaban de que el presidente mexicano había iniciado una campaña diplomática en Centro y Sudamérica preparando el terreno para una condena continental al "imperialismo de Estados Unidos." Un paranoico Sheffield informaba que agentes secretos de México se habían diseminado por el continente con el objetivo "de lograr la independencia de los países latinoamericanos de la influencia de la doctrina Monroe." Hacia 1925, y como prueba de su denuncia, señalaba los sospechosos nombramientos de dos personas "muy identificadas con las ideas nacionalistas de Calles". Se trató de Pascual Ortiz Rubio al frente de la embajada mexicana en Brasil, y el envío del general Amado Aguirre para el desempeño de una importante misión en el marco de la última controversia fronteriza entre Chile y Perú. "Las fuentes fidedignas" del embajador revelaban un plan de dudosa verosimilitud. Eran conocidas las discrepancias entre el dictador peruano Augusto Leguía y el gobierno de México; por un lado la militancia aprista había convertido a México en una de sus bases de operación en América Latina, ${ }^{24}$ pero por otro lado, las diferencias entre ambos gobiernos se hicieron evidentes cuando el peruano mostró una clara inclinación por la causa católica cuando el inicio de la guerra cristera. En este entorno, Sheffield supuso que el gobierno mexicano ubicaba a Perú como un fiel aliado de los Estados Unidos en América del Sur, y por tanto el gobierno de Lima se vería favorecido en la disputa por la soberanía de Arica. La misión de Aguirre habría sido alertar al entonces presidente chileno Arturo Alessandri aconsejándole no aceptar el plebiscito de Arica, prometiendo además la ayuda de México para hacer frente a esta situación. ${ }^{25}$ La encomienda de Aguirre resulta tan increíble como los informes de la embajada norteamericana en La 
Habana, donde otras "fuentes confidenciales" revelaban que el gobierno de México "está haciendo todo lo posible para ser el líder en todos los asuntos latinoamericanos en oposición a los Estados Unidos. ${ }^{26}$ En la primavera de 1926, nuevos informes desde la capital cubana alertaron sobre "los intereses de México de liderar un bloque de países latinoamericanos utilizando como plataforma de lanzamiento el Congreso Postal Panamericano que se realizaría en México al finalizar octubre 1926. George Wythe, agregado comercial en la embajada norteamericana en la capital mexicana, confirmaba aquellas sospechas al afirmar "que los delegados mexicanos no perderán ninguna oportunidad en el Congreso para dominarlo, en donde México tratará de realizar su ambición de convertirse en líder de los países americanos". ${ }^{27}$

Sin duda, en el enfrentamiento con México interesaba al Departamento de Estado conocer la capacidad del gobierno de Calles para articular una solidaria respuesta latinoamericana. De ahí los cablegramas que desde Washington recibía Sheffield solicitando investigaciones de lo conversado entre Calles y distintos diplomáticos latinoamericanos acreditados en México, ${ }^{28}$ de ahí también la vigilancia a la que fueron sometidos los diplomáticos mexicanos en Washington y en Nueva York, sobre todo respecto a sus relaciones con las misiones diplomáticas latinoamericanas. ${ }^{29}$

En realidad todo el actuar mexicano en América Latina fue puesto bajo la lupa de los servicios norteamericanos, tratando de descubrir la trama secreta de un temido plan para liderar la política continental. En marzo de 1926, el agregado militar de la embajada norteamericana, E. Davis, informó que una comisión militar mexicana estaba pronta a partir a Buenos Aires, y que según sus "fuentes confidenciales" el objetivo era conocer la organización militar argentina con los fines de mejorar la mexicana. Dos meses después, desde Buenos Aires, el embajador norteamericano Peter Jay, daba cuenta del arribo de los militares mexicanos junto a un oficial de la reserva del ejército americano, comisionado para espiar a la misión mexicana. ${ }^{30} \mathrm{El}$ peligro de esta misteriosa encomienda se desvanece a juzgar por las referencias que dan cuenta de un viaje exploratorio para la compra de un lote 
de caballos rioplatenses, pero también de la recolección de reglamentos y noticias varias sobre el juego de polo al que era afecto el Gral. Joaquín Amaro. ${ }^{31}$

La conexión centroamericana constituyó el punto más sensible. Nicaragua ocupaba un lugar de primer orden, pero los servicios de inteligencia norteamericanos no tardaron en detectar un accionar mexicano en Guatemala y Honduras. El cónsul norteamericano en Salina Cruz, en junio de 1926 indicaba que el gobierno de México enviaba armas a rebeldes guatemaltecos para ayudar al derrocamiento del presidente José María Orellana, "quien es considerado en México como enemigo de los obreros". Los "informes confidenciales" esta vez consignaban el envío de 140 carabinas máuser que habrían ingresado por El Salvador. ${ }^{32}$ Informado por el Departamento de Estado, el gobierno guatemalteco procedió a contratar los servicios de dos agentes secretos recomendados, como era de esperar, por la propia embajada norteamericana en México. Estos agentes se dieron a la infructuosa tarea de buscar indicios que permitieran confirmar las versiones difundidas por el servicio exterior norteamericano, mientras que el propio presidente Orellana no dejaba de lamentarse por la manera en que el presidente Calles le había correspondió la deferencia "de elevar la representación diplomática a rango de Embajada con perjuicio de las finanzas interiores de Guatemala." 33

Ninguna rebelión signó la suerte de Orellana, por el contrario una angina de pecho lo condujo a la tumba impidiendo que concluyera su periodo presidencial. Lázaro Chacón fue su reemplazante en septiembre de 1926. Pocos meses más tarde, Sheffield volvió a encontrar indicios de participación mexicana en Guatemala, pero esta vez denunciaba un plan secreto por el cual México y su vecino del sur resultarían aliados en lucha contra Estados Unidos. El primer objetivo de esa alianza era derrocar al presidente hondureño Vicente Paz Barahona, quien encabezaba un gobierno impuesto por los marines norteamericanos después de ocupar Tegucigalpa en marzo de 1924. Contra aquella ocupación se había alzado el general Gregorio Ferrera, a la sazón exiliado en México cuando Sheffield anunció este nuevo plan 
mexicano de intervenir en Centroamérica. En febrero de 1927, desde la embajada norteamericana en Ciudad de México salió un cable anunciando el inminente embarque del Ferrera desde Puerto México, al mando una expedición con armas y municiones para ayudar a derrocar gobierno conservador de su país. La noticia fue trasmitida al New York America, periódico de Hearst, quien se encargó de propagarla ampliamente al punto que desde Washington se ordenó una nueva movilización de marines hacia Nicaragua, así como el envío "de una división completa de aeroplanos salidos de la base de San Diego para operaciones en Centroamérica." ${ }^{34} \mathrm{La}$ falsedad de la noticia se hizo evidente cuando días más tarde se ubicó al general Ferrera acompañado del representante de Sandino en México, el nicaragüense Hugo Zepeda, ambos desayunando en el Hotel Regis de la capital del país "sin demasiadas intenciones de salir de México" ${ }^{35}$

En este mismo sentido y con similar suerte, corrió Sheffield al denunciar un supuesto empréstito millonario de México a Guatemala. Un "banquero americano que está en contacto con el Banco Nacional de México me ha informado que dicho banco mandó la semana pasada secretamente dos millones de pesos en monedas de oro mexicana a su sucursal en Suchiate. Suchiate es un pequeño pueblo con dos mil habitantes, comercialmente muerto. Sospecho, escribía el embajador, que el verdadero destino es ayudar al gobierno de Guatemala. Ya he telegrafiado a Geissler (embajador norteamericano en Guatemala) para investigar." ${ }^{36}$ Desde la capital guatemalteca la respuesta fue inmediata, se trataba de un préstamo particular entre los bancos" ${ }^{37}$ Una desesperación por descubrir planes secretos de México se podía respirar en los despachos de la diplomacia norteamericana en América Latina. En marzo de 1927, desde Guatemala el embajador Geissler telegrafío a Sheffield para advertir que partía rumbo a México el secretario de la embajada mexicana, Luis Quintanilla, llevando una muy importante documentación del embajador mexicano Alfonso Cravioto y el presidente Chacón. El cable aseguraba que aquella documentación era gran valor aunque desconocía el contenido. Sheffield llamó de inmediato a su servicio de investigación, pidiéndole que no se detenga en precio 
para conseguir copia de los documentos que trae Quintanilla." 38

En la creación de imágenes de un México bolchevique muy pronto se sumaron los gritos del Vaticano. El conflicto del callismo con la Iglesia rápidamente se instaló en la prensa latinoamericana y de inmediato cristalizó en movilizaciones públicas de sectores conservadores solidarios con los católicos mexicanos. Mientras las batallas del callismo contra la iglesia adquirían dimensiones ejemplares entre los defensores de un liberalismo laico, en la masonería y en buena parte del pensamiento de izquierda; a escala mundial la Iglesia desplegó esfuerzos y recursos para criticar a "esa dictadura monstruosa que quiere convertir a la sociedad mexicana en manada de fieras ejecutando los planes de la masonería y el soviet". ${ }^{39}$ En Brasil, contrariamente a las elucubraciones del embajador Sheffield, los ataques periodísticos al gobierno mexicano estuvieron a punto de desatar una crisis en la relación entre ambos países, cuando el poco diplomático embajador Pascual Ortiz Rubio perdió la paciencia y amenazó con su partida si el gobierno brasileño no frenaba las críticas "antimexicanas" de los sectores ultramontanos de la sociedad carioca. ${ }^{40}$ Frente a la movilización católica en Brasil, fueron escasos los resultados que pudo cosechar la diplomacia callista. Similar panorama se observó en el Río de la Plata, donde el embajador Alfonso Reyes sin hacer púlica su ofuscación, peleaba con firmeza tanto en la cancillería argentina como en las redacciones de los diarios conservadores, tratando de frenar los ataques alentados por esos "de hombres con faldas". ${ }^{41}$

Hacia 1927, México parecía constituir un real factor de perturbación para la política norteamericana en la región. Con la complacencia gubernamental habían proliferado organizaciones de cuño antimperialista, cuyos orígenes remiten a las redes políticas e intelectuales que unieron a mexicanos y latinoamericanos residentes en el país. Entre estas organizaciones destacaron la Liga Antiimperialista de las Américas, la Unión Latino Americana, la Alianza Popular Revolucionaria Americana, la Unión Centro Sud Americana y de las Antillas y el Comité Manos Fuera de Nicaragua. ${ }^{42}$ Aunque 
DIPLOMÁTICOS, PERIODISTAS, ESPÍAS Y PUBLICISTAS:...

con fuertes diferencias ideológicas entre ellas, estas organizaciones coincidieron en el diagnóstico de colocar a la política norteamericana como la principal enemiga en el proyecto de construcción de sociedades más justas e igualitarias. En diciembre de 1926, un informante de la embajada norteamericana, advertía a Sheffield de la complicidad de la embajadora soviética Alexandra Kollontai con la Unión Latinoamericana, organización "directamente relacionada con la Rusia de los soviets que esta haciendo propaganda para lograr en un futuro próximo dominar las Américas con las doctrinas rusas" 43 Las diferencias entre estas organizaciones eran imperceptibles para una diplomacia norteamericana en México que no dejó de escandalizarse ante un incesante desfile de manifestaciones antimperialistas en la puertas de sus oficinas. Sheffield no podía distinguir entre los "elementos rojos encabezados por el socialista Julio Antonio Mella", arengando contra el "capitalismo norteamericano que interviene en Nicaragua y presiona a México por la cuestión del petróleo", ${ }^{44}$ e Isidro Fabela cuando tiempo más tarde, y ante a varios centenares de asistentes a un mitin frente a la embajada, sentenció: "la caída de México es la caída de América Latina." 45

En los agitados veintes, los radicalismos tensaron las relaciones políticas a tal punto que en lo interno una guerra religiosa ensangrentó la nación, mientras que en el plano internacional estuvo a punto de activarse una nueva intervención armada de Estados Unidos. México era un auténtico laboratorio en busca de fórmulas que permitieran alcanzar márgenes de mayor justicia social, y para hacerlo resultaba ineludible ensanchar otros márgenes, los de la autonomía ante los intereses imperiales. Este ejercicio no pudo más que ser calificado como bolchevique, después de todo ¿qué otros referentes podían tener los hombres de Wall Street y los del Departamento de Estado para valorar tremenda aventura mexicana?

Sin embargo, aquellos hombres nunca comprendieron que la estrategia de México era de naturaleza esencialmente defensiva. Lejos de corresponder a una voluntad interesada en 
convertir la experiencia revolucionaria en un modelo exportable, líderes y gobernantes mexicanos tan sólo aspiraron a generar conductas solidarias en diferentes ámbitos del quehacer político latinoamericano. Se trataba de dotar a la Revolución de una cuota de legitimidad internacional regateada por los principales centros del poder mundial. La Revolución fue capaz de despertar solidaridades, pero la estrategia mexicana fue incapaz de generar acciones concretas de parte de los gobiernos latinoamericanos. De ello se lamentaba el diplomático mexicano Oscar Duplán en una carta que en 1923, dirigió a Alfredo Palacios, legislador, profesor universitario y líder del socialismo argentino:

Debo hacer la aclaración que nuestra política no ha sido, como podría creerse, antinorteamericana. Hemos desempeñado un papel defensivo [...] Formamos, como todo el mundo sabe, la vanguardia de los países latinos de este continente, y creemos que hemos cumplido con nuestro deber. Hemos defendido la dignidad y la soberanía nacionales con todo esfuerzo [...] pero he aquí la clave del asunto, hemos lamentado dolorosamente la falta de cooperación en esta lucha de las republicas al sur. [...En América Latina y en nuestro apoyo hubo....] protestas populares, que mucho agradecemos, [pero] no han pasado nunca a la acción de los gobiernos. En este sentido nunca hemos recibido colaboración. Las cancillerías latinoamericanas nada práctico han hecho, y no solo eso, sino que por otra parte, algunas veces hasta de instrumento han servido al gobierno de la Casa Blanca. ${ }^{46}$

Duplán estaba en lo cierto, el gran esfuerzo por dar a conocer la Revolución, despertó entusiasmos en círculos universitarios, en segmentos del movimiento obrero, en las logias masónicas y en espacios políticos e intelectuales del progresismo latinoamericano de aquel entonces; pero en la arena de la política exterior no fueron visibles acciones concretas tendientes a defender la soberanía mexicana.

El presidente Calles no ignoró esta realidad y justamente por ello, por paradójico que resulte, no cejó en su campaña de propaganda, como tampoco en las tareas de espionaje que le 
DIPLOMÁTICOS, PERIODISTAS, ESPÍAS Y PUBLICISTAS:...

permitieron conocer las ideas y las acciones que aquella campaña alentaba en el gobierno estadounidense. Calles no podía despertar políticas solidarias entre los gobiernos del continente, pero sí pudo hacer creer que esas políticas tendrían lugar. $Y$ esto fue así porque el esfuerzo publicitario fue directamente proporcional al pavor norteamericano de ver convertido a México en un soviet. De suerte que Calles, gracias a la lectura que de sus acciones hicieron los servicios de inteligencia norteamericanos, terminó por adquirir una dimensión agigantada, capaz de dotar al país de una enorme habilidad y fortaleza para interferir en cuestiones centrales de la política hemisférica. Nada de ello fue cierto, se trató al final de cuentas de un país maltrecho, pero gobernado con la sagacidad de unos norteños que no solo desconfiaban de sus sombras, sino y fundamentalmente del gobierno de los Estados Unidos.

YANKELEVICH, Pablo. Diplomats, journalists, spies and publicists: The Mexican-Bolshevik campaign in Latin America. História, v.28, n.2, p.495-514, 2009.

Abstract: In the mid-20s important sectors within President John Calvin Coolidge's administration as well as American public opinion were convinced that Mexico had found itself governed by a group of communists. This idea arose due to an unsolved conflict, which the Mexican revolutionaries had had with the government and American businessmen since the preparation of the 1917Constitution. This was added to a series of actions of President Calles challenging sectors within Mexican society as well as the powerful interests of the Americans. In this text strategies and characters are studied that contributed to the evolution of the idea of a soviet Mexico, paying particular attention not only to the work developed by spies at the service of the American government, but also to the work of the intellectuals that under the Callista protection took on a complete and comprehensive job of spreading anticlerical and antiimperialist propaganda.

Keywords: Mexico; Revolution; Communism; Anticommunism; Propaganda; Espionage. 


\section{NOTAS}

${ }^{1}$ Fideicomiso Archivos Plutarco Elías Calles y Fernando Torreblanca, Archivo Plutarco Elías Calles, (FAPECFT, APEC) anexo caja 36 exp. 748, f. 27

${ }^{2}$ FAPECFT, APEC, gaveta 36, exp. 739, f. 62.

${ }^{3}$ Véase Robert Smith Freeman, The United States and revolutionary nationalism in Mexico, 1916-1932, Chicago, University of Chicago, 1972.

${ }^{4} \mathrm{Al}$ respecto y sobre la política soviética hacia México, véase Daniela Spenser, El triángulo imposible, México, Rusia soviética y Estados Unidos en los años veinte, México, CIESAS-Miguel Ángel Porrúa Ed., 1998

${ }^{5}$ FAPECFT, APEC, fondo 6542, serie 4634, gaveta 63, exp.80, f. 3.

${ }^{6}$ FAPECFT, APEC, gaveta 18, exp. 202, inventario 1218, f. 6.

${ }^{7}$ FAPECFT, APEC, fondo 791, serie 678, gaveta 10, exp.125, leg. 1/2, f. 45.

${ }^{8}$ FAPECFT, APEC, fondo 1622, serie 1301, gaveta 26, exp.54, leg.1/2.

9 FAPECFT, APEC, fondo 3649, serie 2902, gaveta 43, exp. 37, f.1. Respecto a la nota de José Ingenieros, se trató de la reproducción del artículo titulado "Regreso de Ingenieros" (Revista de Filosofía. Buenos Aires, Vol. XXV, septiembre de 1925), donde el intelectual argentino dio cuenta de sus impresiones al regresar de México después de su única visita y poco antes de su muerte. En ese texto, se explayó sobre la personalidad de Calles, resultando llamativos ciertos giros apologéticos, poco frecuentes en sus escritos: "Debo afirmar mi profunda admiración por el presidente Calles, es un hombre surgido del pueblo, -ex maestro de escuela- cuyas ideas sobre todos los problemas políticos y sociales de su país son claras, definidas y típicamente mexicanas. No hay aspecto del problema gubernativo que no domine a la perfección, y no creo que haya en América, y quizás en el mundo ningún gobernante que interprete más sabiamente y con mayor fidelidad el sentir verdadero de su pueblo". (p.477-478).

${ }^{10}$ Los otros títulos propuestos fueron: El libertinaje artístico y las sátiras anticlericales en las obras pictóricas escultóricas de catolicismo; La mujeres célebres del Vaticano. Las trece amantes del Papa Pío IX, y La iglesia católica ante la ciencia. Un héroe en el drama de la ciencia contra el oscurantismo: Galileo Galilei

${ }^{11}$ FAPECTF, APEC, fondo 1787, serie 1449, gaveta 44, exp. 11, leg.1/2, fol. 47. 
DIPLOMÁTICOS, PERIODISTAS, ESPÍAS Y PUBLICISTAS:...

${ }^{12}$ FAPECTF, APEC, fondo 1787, serie 1449, gaveta 44, exp. 11, leg.1/2, fol. 41 .

${ }^{13}$ FAPECTF, APEC, fondo 1787, serie 1449, gaveta 44, exp. 11, leg.2/2, f .76.

${ }^{14}$ FAPECTF, APEC, fondo 1787, serie 1449, gaveta 44, exp. 11, leg.2/2, f. 80.

${ }^{15}$ FAPECTF, APEC, fondo 1787, serie 1449, gaveta 44, exp. 11, leg.2/2, f. 98

16 Plutarco Elías Calles, "Discurso de apertura de sesiones del Congreso, el $1^{\circ}$ de Septiembre de 1925", en G. Estrada, Un siglo de relaciones internaciones de México a través de los mensajes presidenciales, México, SRE, 1935, p. 397.

17 Sobre la gestión de Gracidas en Sudamérica, véase: Pablo Yankelevich, "Imitemos a México. La experiencia de Carlos Gracidas en la diplomacia obrera mexicana (1925-1928) en Journal of Iberian and Latin American Studies (JILAS), La Trobe University, Australia, Julio 2001; referencias generales a las agregadurías obreras pueden consultarse en Ruth .M. Clark, La organización obrera en México, México, ed. ERA, 1979, p. 232 y ss.)

${ }^{18}$ Friedrich Katz, "El gran espía de México", Boletín núm. 20 del Fideicomiso Archivos Plutarco Elías Calles y Fernando Torreblanca, México, FAPECFT, 1995

${ }^{19}$ FAPECFT, APEC, (anexo) caja 31-32, exp. 628, f. 2.

${ }^{20}$ FAPECFT, APEC, (anexo) caja 31-32, exp. 614, f.5.

${ }^{21}$ FAPECFT, APEC, (anexo) caja 31-32, exp. 614, f.15.

${ }^{22}$ FAPECFE, APEC, fondo 1804, serie 1461, gaveta 28, exp. 24 , f. 7.

${ }^{23}$ Jürgen Buchenau, In the sadow of the giant. The making of Mexico's Central America Policy, 1876-1930, Alabama, The University of Alabama Press, 1996; Michel Dospital, "La herencia mexicana en la lucha sandinista de los años 20 en Nicaragua", en Secuencia, México, Instituto Mora, $\mathrm{N}^{\circ}$ 30, Sep-Dic.,1994; Carlos Villanueva Sandino en Yucatán. 1929-1930, SEP, México, 1988; y Gregorio Selser, El pequeño ejército loco. Sandino y la operación México-Nicaragua, México, Ed. Bruguera, 1980.

${ }^{24}$ Véase Ricardo Melgar Bao; Redes e imaginario del exilio en México y América Latina. 1934-1940, Buenos Aires, Ediciones Libros en red, 2003.

${ }^{25}$ FAPECFT, APEC, (anexo) caja 31-32, exp. 634. fs. 1 y 2.

${ }^{26}$ FAPECFT, APEC (anexo) caja 31-32 exp. 615, fol. 8. 
${ }^{27}$ FAPECFT, APEC (anexo) caja 31-32 exp. 615, fol. 5.

${ }^{28}$ FAPECFT, APEC (anexo) caja 36 exp. 739, f. 45.

${ }^{29}$ FAPECFT, APEC (anexo) caja 36 exp. 741, f. 49.

${ }^{30}$ FAPECFT, APEC (anexo) caja 35 exp. 706, f. 1; y FAPECFT. APEC (Anexo) caja 31-32 exp. 625, f. 4.

31 FAPECFT, Archivo Joaquín Amaro, serie 0301, exp. 40, inventario 158. leg. 11, f. 651 ; y serie 0304, exp. 32 , inventario 262 , leg. 1 , f. 3.

${ }^{32}$ FAPECFT, APEC, (anexo) caja 36, exp. 738, f. 22.

${ }^{33}$ FAPECFT, APEC, (anexo) caja 36, exp. 739, f. 52.

${ }^{34}$ FAPECFT, APEC, (anexo) caja 36 exp. 747, f. 7.

${ }^{35}$ FAPECFT, APEC, (anexo) caja 36 exp. 747, f. 20.

${ }^{36}$ FAPECFT, APEC, (anexo) caja 36 exp. 747, f. 36.

${ }^{37}$ FAPECFT, APEC, (anexo) caja 36 exp. 747, f. 54.

${ }^{38}$ FAPECFT, APEC, (anexo) caja 36 exp.748, f.17.

${ }^{39}$ El Pueblo, Buenos Aires, 19 de noviembre de 1927.

${ }^{40}$ Respecto a la campaña católica en Brasil, véase: Guillermo Palacios, Intimidades, conflictos y reconciliaciones. México y Brasil 1822-1993, México, SRE, 2001, pp. 176 y ss.

41 "Carta de Alfonso Reyes a Genaro Estrada, Buenos Aires, 1 de junio de 1928", en Sergei Zaïtzeff, (Comp. y notas) Con leal franqueza, Correspondencia entre Alfonso Reyes y Genaro Estrada, México, El Colegio Nacional, 1992, Tomo II, p 138.

${ }^{42}$ Véase: Alexandra Pita González, Intelectuales, integración e identidad regional: la Unión Latino Americana y el Boletín Renovación, 1922-1930, Tesis de Doctorado, CEH, El Colegio de México, 2004; Daniel Alejandro Kersffeld Demner, La recepción del marxismo en América Latina y su influencia en las ideas de integración continental: El caso de la Liga Antiimperialista de las Américas, México, Tesis de Doctorado en Estudios Latinoamericanos, UNAM, 2007, y Ricardo Melgar Bao: Redes e imaginario del exilio en México y América Latina. 1934-1940, Buenos Aires, Ediciones Libros en red, 2003, y "Un neobolivarismo antimperialista. La Unión Centro Sud Americana y de las Antillas (UCSAYA)", en Políticas de la Memoria, número 6/7, CEDINCI, Buenos Aires, Verano 2006/2007, pp. 149-164

${ }^{43}$ FAPECFT, APEC, (anexo) caja 30, exp. 582, f. 4.

${ }^{44}$ FAPECFT, APEC, (anexo) caja 36, exp. 746, f. 45.

${ }^{45}$ FAPECFT, APEC, (anexo) caja 36, exp. 746, f. 49.

${ }^{46}$ FAPECFT, APEC, fondo 2021, serie 1649, gaveta 25, exp.183, fs. 3 y 4.

Artigo recebido em 08/2009. Aprovado em 11/2009. 